Check for updates

Cite this: RSC Adv., 2017, 7, 19497

Received 6th February 2017

Accepted 28th March 2017

DOI: 10.1039/c7ra01507k

rsc.li/rsc-advances

\section{Optical and electrical switching of cholesteric liquid crystals containing azo dye}

\author{
Seung-Won Oh, (D) Jong-Min Baek, Sang-Hyeok Kim and Tae-Hoon Yoon (D) * \\ We propose an optically and electrically switchable cholesteric liquid crystal (ChLC) cell doped with a push- \\ pull azo dye. When the proposed ChLC cell is exposed to UV light, it is switched from the focal-conic to \\ isotropic state by a cholesteric-isotropic phase transition through a trans-cis photo-isomerization of \\ push-pull azo dye molecules. With removal of UV light, the ChLC cell will rapidly relax back to its initial \\ state without exposure to a second light source that has a longer wavelength. We confirmed that the \\ proposed optically and electrically switchable ChLC cell can be used as a smart window that can be \\ switched on by applying sunlight or an electric field.
}

\section{Introduction}

Recently, photochemically-induced phase transitions have become technologically attractive and important because of their smart optical properties. ${ }^{1-3}$ Photochromic compounds, such as azo dyes, spiropyran, and diarylethene, have been intensively studied as candidates for the direct photo-induced phase transition. It is well known that the conformational change between the trans and cis isomers of an azo dye can be applied to control the macroscopic molecular order. ${ }^{4-11}$ Liquid crystals (LCs) mixed with azo dyes undergo a significant change in the order parameter as a result of trans-cis photo-isomerization, ${ }^{\mathbf{1 2 - 1 5}}$ which lowers the clearing point of the LC mixture over the course of continuous UV exposure. Thus, LC devices can be switched optically by a nematic-isotropic phase transition.

Meanwhile, cholesteric LCs (ChLCs) are typically characterized by a helical structure, resulting in selective reflection of the incident light in the planar state and scattering of the light in the focal conic state. Especially, switching between the focal conic and homeotropic states can be applied as a switchable reflector for reflective displays and light shutters. ${ }^{\mathbf{1 6 - 1 8}}$ Optically controllable ChLC devices can be fabricated simply by doping azo dye to LCs. ${ }^{13}$ However, although the trans-cis isomerization is rapidly induced, the cis-trans isomerization typically takes tens of hours. To return to the initial state rapidly, a second light source with a longer wavelength is required that can induce the cis-trans photo-isomerization. Slow relaxation and the requirement of two light sources can make it difficult practical display or smart window application.

In this study, we propose an optically and electrically switchable ChLC cell doped with push-pull azo dye, which is known to speed up thermal relaxation. When the proposed ChLC cell is exposed to

Department of Electronics Engineering, Pusan National University, Busan 46241, Korea. E-mail: thyoon@pusan.ac.kr; Fax: +82-51-515-5190; Tel: +82-51-510-2379
UV light, it is switched from the focal conic to the isotropic state by cholesteric-isotropic phase transition through trans-cis photoisomerization of push-pull azo dye molecules. With the UV light is removed, the ChLC cell rapidly relaxes back to its initial state. We have shown that the proposed ChLC cell can be optically switchable between the focal conic and isotropic states by sunlight, and electrically switchable between the focal conic and homeotropic states by applying a vertical electric field. An optically and electrically switchable ChLC cell, which enables transition between the translucent and transparent states depending upon the ambient conditions, will be a promising approach for a smart window.

\section{Experimental}

\subsection{Materials}

We mixed LCs to set the switching temperature range, which depends on the clearing point of the LCs. Fig. 1 shows the chemical structure, clearing point, and percentage of LCs in the mixture used in this study. The LC mixture consists of four

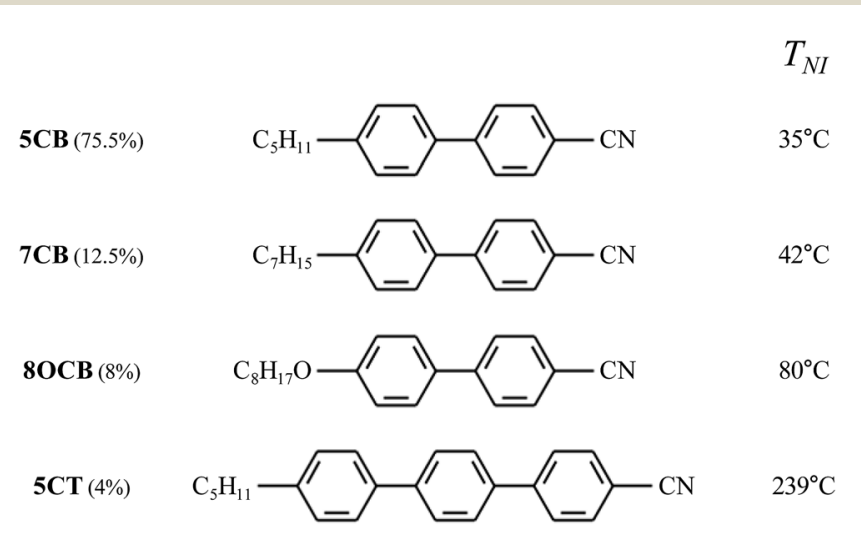

Fig. 1 Structures and wt\% of the components present in the nematic mixture $(5 \mathrm{CB}, 7 \mathrm{CB}, 80 \mathrm{CB}$, and $5 \mathrm{CT}$ ) used in our experiment. 


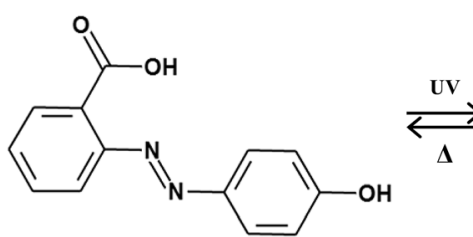

trans-HABA
cis-HABA

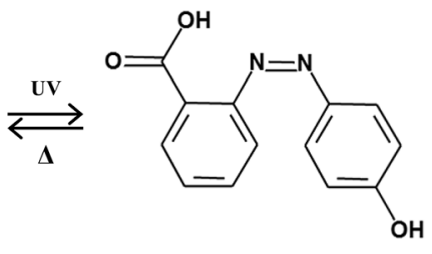

Fig. 2 Trans-cis isomerization of push-pull azo dye HABA.

compounds: $\quad 4^{\prime}-n$-pentyl-4-cyanobiphenyl (5CB), 4'-n-heptyl-4cyanobiphenyl (7CB), $4^{\prime}$-n-octyloxy-4-cyanobiphenyl (8OCB), and $4^{\prime}-n$-pentyl-4-cyano- $p$-triphenyl (5CT). The clearing point of the mixture was $48.1{ }^{\circ} \mathrm{C}$, which can be decreased by doping chiral material. To overcome the slow cis-trans isomerization, we can use push-pull azo dye HABA (2-(4-hydroxyphenylazo)benzoic) acid which has been used to speed up thermal relaxation (Fig. 2). ${ }^{20,21}$

\subsection{Cell fabrication}

The LC mixture was doped with chiral dopant S-811 and HABA by stirring continuously for $24 \mathrm{~h}$ at room temperature. In order to apply a vertical electric field for electrical switching, the top and bottom substrates contain the transparent indium-tin-oxide electrodes. Indium-tin-oxide-coated glass substrates were subjected to several cleaning steps before the spin-coating process. To obtain the ChLC cells with vertical anchoring at surfaces, we used polyimide SE-5662 (Nissan, Japan), which was spin-coated on each substrate. Spin coating was made at $3000 \mathrm{rpm}$, for $30 \mathrm{~s}$. The coated substrates were pre-baked at $100{ }^{\circ} \mathrm{C}$ for $10 \mathrm{~min}$ on a hot plate and annealed at $180^{\circ} \mathrm{C}$ for $1 \mathrm{~h}$. The mixture was filled to a $20 \mu \mathrm{m}$-thick cell via capillary action at room temperature.

\subsection{Measurements}

The measurement of the clearing point was carried out using a Mettler FP82 hot-stage and a Mettler FP90 controller. The specular transmittance was measured using a spectrometer (MCPD 3000, Photal) covering from 380 to $780 \mathrm{~nm}$. The fabricated ChLC cell was exposed to unpolarized UV light (365 nm) using a mercury arc lamp (Osram HBO $103 \mathrm{~W} / 2$ ). The electrooptical performance of the fabricated ChLC cell was measured using a haze meter (HM-65W, Murakami Color Research Laboratory). The specular [diffuse] transmittance $T_{\mathrm{s}}\left[T_{\mathrm{d}}\right]$ refers to the ratio of the power of the beam that emerges from a sample cell, which is parallel (within a small range of angles of $2.5^{\circ}$ ) [not parallel] to a beam entering the cell, and to the power carried by the beam entering the sample. The total transmittance $T_{\mathrm{t}}$ is the sum of the specular transmittance $T_{\mathrm{s}}$ and the diffuse transmittance $T_{\mathrm{d}}$. The haze $H$ can be calculated as the ratio $H=T_{\mathrm{d}} / T_{\mathrm{t}}$.

\section{Results and discussion}

\subsection{Optically and electrical switching of a ChLC cell}

To confirm the use of the proposed ChLC cell as a switchable reflector, we fabricated the ChLC cell with the initial focal conic state. The initial focal conic state can be obtained with sufficiently strong homeotropic anchoring. ${ }^{22-24}$ The minimal helical pitch value for the homeotropic state can be expressed as

$$
P_{\text {th }}=2 d K_{22} / K_{33},
$$

where $d$ is the cell gap, and $K_{22}$ and $K_{33}$ are elastic constants for twist and bend deformations, respectively. If the pitch is larger than the threshold pitch $P_{\text {th }}$, the chiral torque is too weak and the system is unable to twist, resulting in homeotropic alignment of LCs. When the pitch is smaller than $P_{\text {th }}$, the chiral torque is sufficiently strong, and the initial focal conic state can be observed.

Fig. 3 depicts the specular transmittances, haze values, and photographs of ChLC cells with vertical anchoring at surfaces as a function of the number of pitches. The number of pitches was varied by changing the chiral dopant concentration for a fixed cell gap. As we expected from eqn (1), the homeotropic state can be obtained when the number of pitches is smaller than 2 because the calculated minimal helical pitch value for the homeotropic state is approximately $1 \mu \mathrm{m}$. As the number of pitches is increased, the specular transmittance decreases and the haze gradually increases. The measured haze value was saturated and we can hide the printed texts when the number of pitches reached 16, which was chosen as the initial focal conic state of the proposed ChLC cell.

We measured the clearing point of the LC mixture without chiral dopant as a function of the HABA concentration, as shown in Fig. 4(a). Before UV irradiation, the clearing point does not change with the increase of HABA concentration. Once the mixture is irradiated by UV light and the trans-cis photoisomerization takes place, the bent shape of the cis-azo dye introduces molecular disorder in the mixture. ${ }^{21}$ Thus, the clearing point is lowered. When exposed to UV light, the clearing point of the mixture (HABA $5 \mathrm{wt} \%$ ) changed from $47^{\circ} \mathrm{C}$ to $38{ }^{\circ} \mathrm{C}$. It should be noted that the switching temperature of the proposed ChLC cell depends on the LC material.

It is well known that LCs with a high molecular weight of chiral dopant can decrease the clearing point of the mixture. ${ }^{19}$ To investigate the switching temperature of the proposed ChLC cell, we fabricated a ChLC cell and measured the specular transmittance with and without UV irradiation as a function of
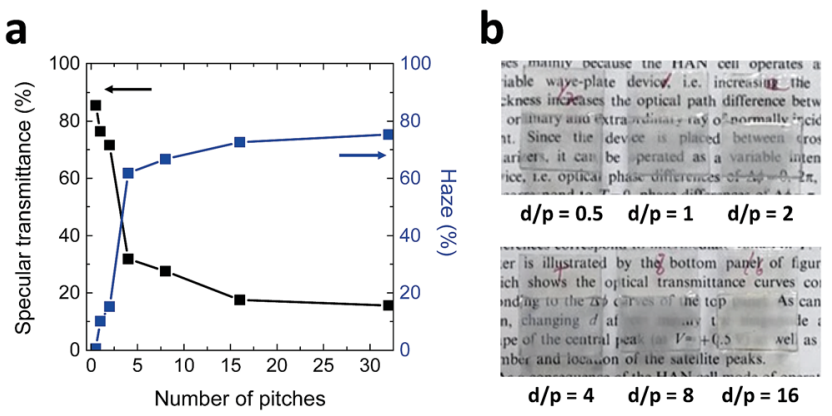

Fig. 3 (a) Specular transmittances and haze values and (b) photographs of ChLC cells with vertical anchoring at surfaces as functions of the number of pitches. 
a

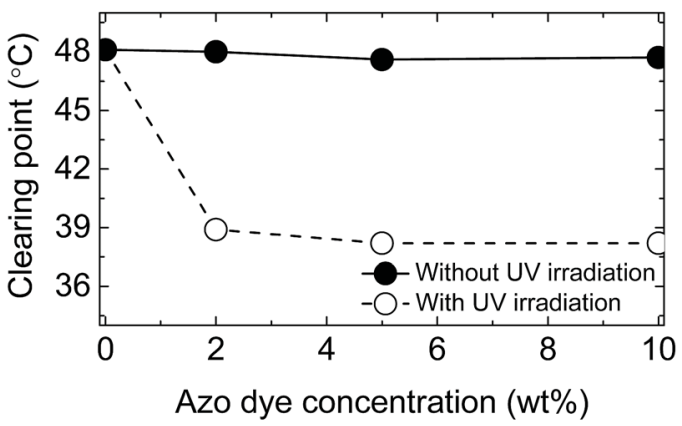

b

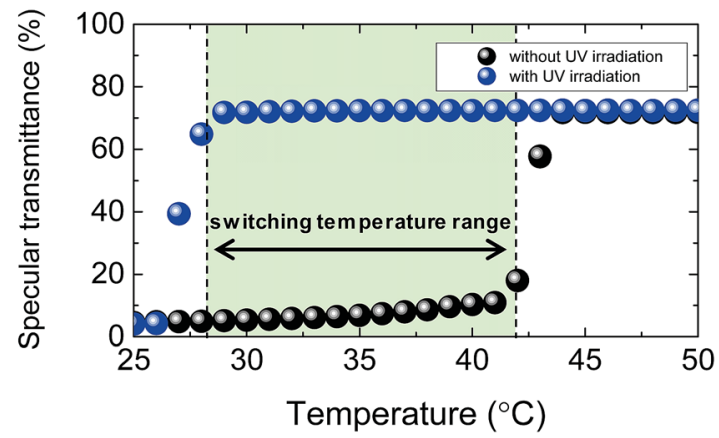

Fig. 4 (a) Clearing point of the LC mixture as a function of HABA concentration. (b) The specular transmittance of the fabricated ChLC cell with and without UV irradiation as a function of temperature.

temperature. The fabricated ChLC cell was exposed to unpo-

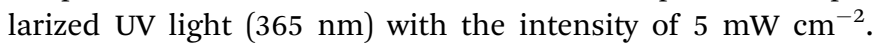
Concentrations of azo dye and chiral dopant were 5 and 7.53 $\mathrm{wt} \%$, respectively. Fig. 4(b) shows a plot of the variation in transmittance of the proposed ChLC cell with temperature. Without UV irradiation, the transmittance abruptly increased at approximately $44{ }^{\circ} \mathrm{C}$ during the heating process. This temperature is close to the clearing point. The clearing point was decreased from $47^{\circ} \mathrm{C}$ to $44^{\circ} \mathrm{C}$ by doping a chiral dopant. With UV irradiation, the transmittance abruptly increased at approximately $29^{\circ} \mathrm{C}$ during the heating process. In other words, the phase transition of the LC mixture between the cholesteric and isotropic states can be controlled by UV light for temperatures ranging from $29{ }^{\circ} \mathrm{C}$ to $44{ }^{\circ} \mathrm{C}$. We should note that the switching temperature range was also increased from $9{ }^{\circ} \mathrm{C}$ to $15{ }^{\circ} \mathrm{C}$ by doping chiral dopant. Although the switching temperature range of the proposed ChLC cell is currently rather narrow, we expect that the temperature range can be widened further by developing new azo dye materials.

To confirm optical switching, we fabricated the proposed ChLC cell by exposing to UV light with the intensity of $5 \mathrm{~mW}$ $\mathrm{cm}^{-2}$. Fig. 5(a) shows changes in the specular transmittance of a ChLC cell fabricated by UV irradiation at $30{ }^{\circ} \mathrm{C}$. Before UV irradiation, the transmittance was kept at about $4 \%$. The transmittance was increased by UV irradiation and thermally relaxed with removal of UV light. The transition took place in around $30 \mathrm{~s}$. The transition from the isotropic to the focal conic state can be achieved without any external power or light because the proposed ChLC cell contains the push-pull azo dye which has the fast thermal relaxation property.

To confirm electrical switching, the total transmittance, specular transmittance, and haze of the fabricated ChLC cell as functions of the applied voltage are shown in Fig. 5(b). In the initial focal conic state (opaque state), the measured total transmittance, specular transmittance, and haze of the fabricated ChLC cell were $65.2 \%, 18.1 \%$, and $72.2 \%$, respectively. Haze decreased gradually as the applied voltage increased to $18 \mathrm{~V}$, but the haze increased at higher applied voltages. This increase in haze is caused by ion impurities that generate dynamic scattering. ${ }^{25-28}$ When the applied voltage was higher than $40 \mathrm{~V}$, LCs were aligned homeotropically along the direction of the applied field. In the homeotropic state, light scattering was minimized. The measured total transmittance, specular transmittance, and haze in the homeotropic state were $83.6 \%, 81.5 \%$, and $2.5 \%$, respectively.

\subsection{ChLC cell for smart window applications}

Although the proposed ChLC cell exhibits fast thermal relaxation, optical switching of the proposed ChLC cell is still much a

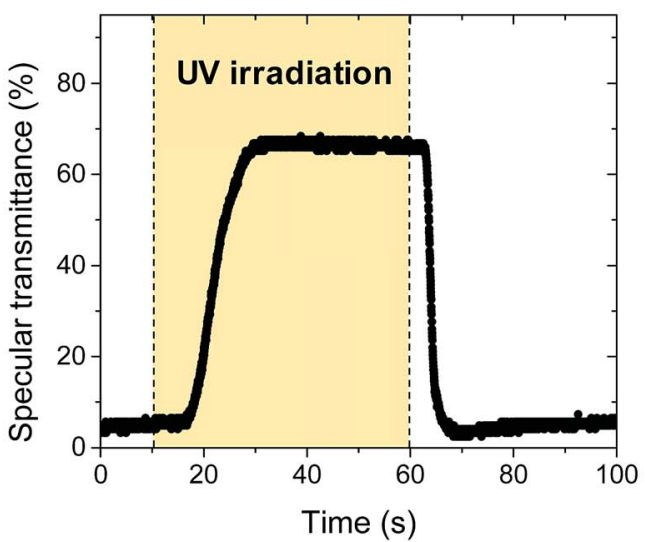

b

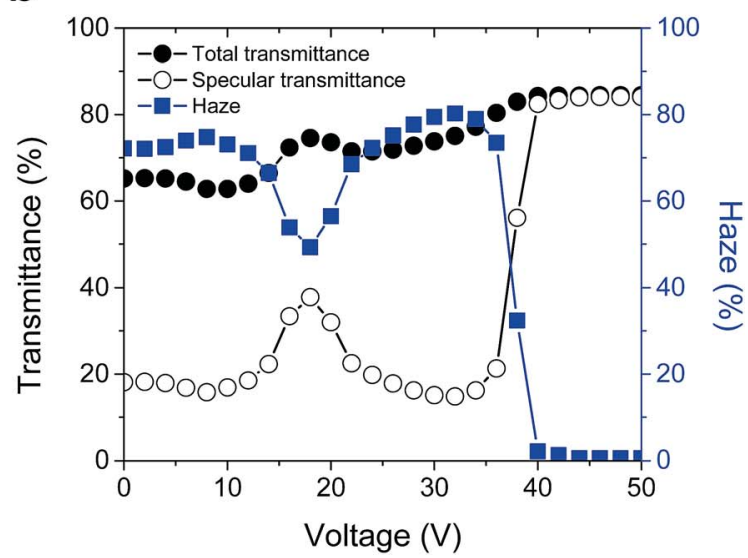

Fig. 5 (a) Changes in specular transmittance of fabricated ChLC cell by UV irradiation at $30{ }^{\circ} \mathrm{C}$. (b) Total transmittance, specular transmittance, and haze of fabricated ChLC cell as functions of the applied voltage. 
slower than electrical switching. Therefore, its main application can be a smart window rather than optical components requiring a fast response time. Its optical switching time is similar to other smart window devices, such as electrochromic, thermochromic, and photochromic devices. ${ }^{29-31}$ A simple illustration of the proposed ChLC cell as a smart window is shown in Fig. 6. In the initial translucent state, the incident light is scattered by LCs in the focal conic state as a result of the randomly oriented ChLCs. The optical switching mechanism is based on the change of the LC order parameter by the photoisomerization effect of push-pull azo dye. Under sunlight irradiation, the cell was switched from the focal conic to isotropic state by cholesteric-isotropic phase transition of the LCs triggered by trans-cis photo-isomerization of push-pull azo dye molecules. When the intensity of sunlight was low because of cloud cover or when there was little sunlight at sunset, the cell rapidly relaxed from the isotropic state back to its initial focal conic state. It can be switched from the translucent to transparent state by applying an electric field, too. Under an applied vertical electric field, the focal conic state is switched to the homeotropic state and the cell becomes transparent.

Photographs of the proposed smart window placed on printed texts in the focal conic, homeotropic, isotropic states are shown in Fig. 7(a). In the focal conic state, the proposed smart window can scatter the incident light by the refractive index difference between LC domains. In the homeotropic and isotropic states, we can identify characters behind a panel clearly. The measured specular transmittances were $9.40 \%, 67.1 \%$, and $66.9 \%$ in the focal conic, homeotropic, isotropic states, respectively. The optically-induced isotropic state showed nearly the same specular transmittance as the electrically-induced homeotropic state.

Fig. 7(b) shows the results of an outdoor switching test performed under sunlight for an optically and electrically switchable smart window and a ChLC cell. The measured temperature of the fabricated cells was approximately $30^{\circ} \mathrm{C}$ when irradiated with sunlight. In the initial state, both cells were translucent and blocked the view. When exposed to sunlight, the cell doped with HABA became transparent and the background scene was clearly visible, whereas the typical ChLC cell was still translucent. As soon as we blocked the sunlight, the cell doped with

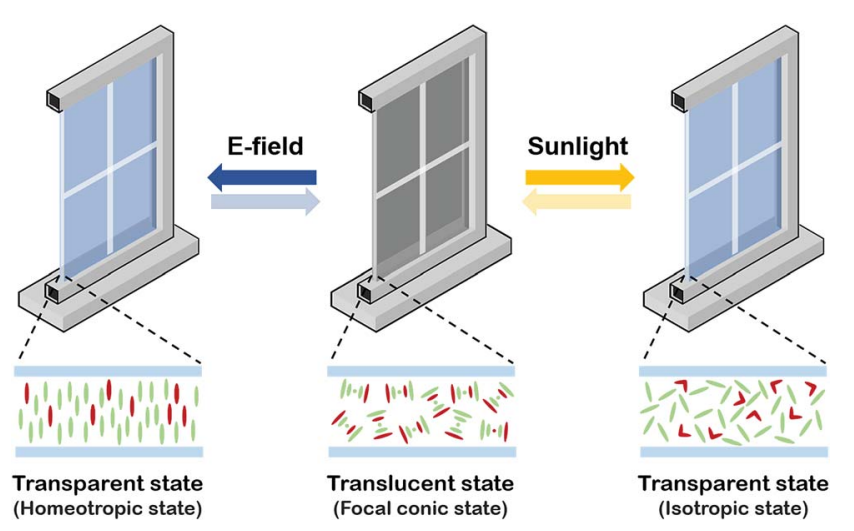

Fig. 6 Schematic representation of the proposed smart window using a push-pull azo dye.

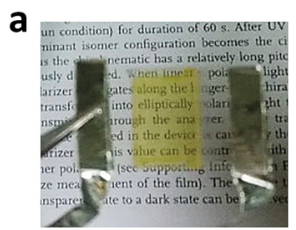

Homeotropic state

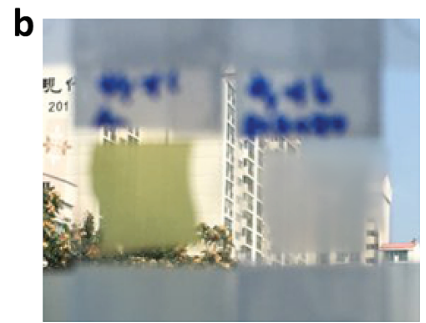

weak sunlight

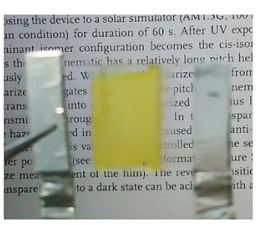

Focal conic state

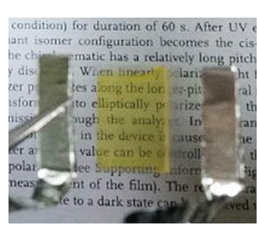

Isotropic state

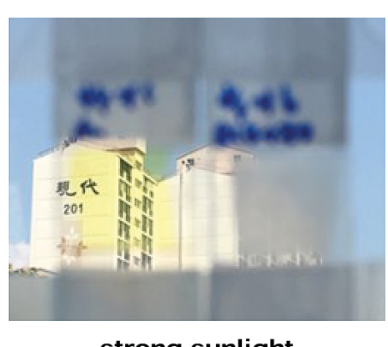

strong sunlight

Fig. 7 (a) Photographs of the proposed smart window in three states. (b) Photographs of the proposed smart window (left) and typical ChLC cell (right) under the outdoor environment.

HABA returned to its initial translucent state within $30 \mathrm{~s}$. We should note that the transition between these states was achieved without any external power or signal.

\section{Conclusions}

An optically and electrically switchable ChLC cell doped with push-pull azo dye was demonstrated. The proposed ChLC cell is switchable between the focal conic and homeotropic states by applying an electric field or between focal conic and isotropic states by UV irradiation. Its main application can be a smart window rather than optical components requiring a fast response time because optical switching of the proposed ChLC cell is much slower than electrical switching. Under sunlight irradiation, the proposed ChLC cell was switched from the translucent to the transparent state. When the intensity of sunlight was low because of cloud cover, or when there was little sunlight at sunset, the proposed ChLC cell rapidly relaxed without exposure to a second light source that had a longer wavelength. With such a proposed ChLC cell as a smart window, we could clearly see the outside through the window during the daytime, while blocking the view of the indoor area for privacy during the night without any external power or signal. Moreover, when the temperature is out of the sunlight-switchable temperature range, it can be switched between the translucent and transparent states by applying an electric field.

\section{Acknowledgements}

This work was supported by the IT R\&D program of MOTIE/ KEIT [10042412, More than 60 Transparent Flexible Display with UD Resolution, Transparency $40 \%$ for Transparent Flexible Display in Large Area] and the National Research Foundation of Korea (NRF) grant funded by the Korean government (MSIP) (No. 2017R1A2A1A05001067). 


\section{Notes and references}

1 S. Kobatake, H. Imagawa, H. Nakatani and S. Nakashima, New J. Chem., 2009, 33, 1362.

2 R. Klajn, P. J. Wesson, K. J. M. Bishop and B. A. Grzybowski, Angew. Chem., Int. Ed., 2009, 48, 7035.

3 L. H. Urner, B. N. S. Thota, O. Nachtigall, S. Warnke, G. Helden, R. Haag and K. Pagel, Chem. Commun., 2015, 51, 8801.

4 D. Y. Kim, S. K. Tripathy, L. Li and J. Kumar, Appl. Phys. Lett., 1995, 66, 1166.

5 T. Ikeda and O. Tsutsumi, Science, 1995, 268, 1873.

6 M. Yamada, M. Kondo, J. Mamiya, Y. Yu, M. Kinoshita, C. J. Barrett and T. Ikeda, Angew. Chem., Int. Ed., 2008, 47, 4986.

7 M. Yamada, M. Kondo, R. Miyasato, Y. Naka, J. Mamiya, M. Kinoshita, A. Shishido, Y. Yu, C. J. Barrett and T. Ikeda, J. Mater. Chem., 2009, 19, 60.

8 M. Irie, Photochem. Photobiol. Sci., 2010, 9, 1535.

9 J.-D. Lin, M.-H. Hsieh, G.-J. Wei, T.-S. Mo, S.-Y. Huang and C.-R. Lee, Opt. Express, 2013, 21, 15765.

10 K. Masutani, M. Morikawa and N. Kimizuka, Chem. Commun., 2014, 50, 15803.

11 J.-D. Lin, C.-P. Chen, L.-J. Chen, Y.-C. Chuang, S.-Y. Huang and C.-R. Lee, Opt. Express, 2016, 24, 3112.

12 J. P. Otruba III and R. G. Weiss, J. Org. Chem., 1983, 48, 3448.

13 Y. Kawanishi, T. Tamaki and K. Ichimura, J. Phys. D: Appl. Phys., 1991, 24, 782.

14 J. Bin and W. S. Oates, Sci. Rep., 2015, 5, 14654.

15 S.-W. Oh, J.-M. Baek and T.-H. Yoon, Opt. Express, 2016, 24, 26575.
16 K.-H. Kim, H.-J. Jin, D. H. Song, B.-H. Cheong, H.-Y. Choi, S. T. Shin, J. C. Kim and T.-H. Yoon, Opt. Lett., 2010, 35, 3504.

17 K.-H. Kim, H.-J. Jin, K.-H. Park, J.-H. Lee, J. C. Kim and T.-H. Yoon, Opt. Express, 2010, 18, 16745.

18 K.-H. Kim, D. H. Song, Z.-G. Shen, B. W. Park, K.-H. Park, J.-H. Lee and T.-H. Yoon, Opt. Express, 2011, 19, 10174.

19 U. A. Hrozhyk, S. V. Serak, N. V. Tabiryan and T. J. Bunning, Adv. Mater., 2007, 19, 3244.

20 P. El-Kallassi, R. Ferrini, L. Zuppiroli, N. L. Thomas, R. Houdré, A. Berrier, S. Anand and A. Talneau, J. Opt. Soc. Am. B, 2007, 24, 2165.

$21 \mathrm{H}$. Yu and T. Kobayashi, Molecules, 2010, 15, 570.

22 P. E. Cladis and M. Kléman, Mol. Cryst. Liq. Cryst., 1972, 16, 1.

23 P. Oswald, J. Baudry and S. Pirkl, Phys. Rep., 2000, 337, 67.

24 I. Gvozdovskyy, O. Yaroshchuk, M. Serbina and R. Yamaguchi, Opt. Express, 2012, 20, 3499.

25 D.-K. Yang and S.-T. Wu, Fundamentals of Liquid Crystal Devices, Wiley, 2006.

26 G. H. Heilmeier, L. A. Zanoni and L. A. Barton, Proc. IEEE, 1968, 56, 1162.

27 G. H. Heilmeier, L. A. Zanoni and L. A. Barton, Appl. Phys. Lett., 1968, 13, 46.

28 G. H. Heilmeier, L. A. Zanoni and L. A. Barton, IEEE Trans. Electron Devices, 1970, 17, 22.

29 A. Seeboth and D. Lötzsch, Thermochromic and Thermotropic Materials, 2013.

30 R. J. Mortimer, D. R. Rosseinsky and P. M. Monk, Electrochromic Materials and Devices, 2015.

31 H. Tian and J. Zhang, Photochromic Materials: Preparation, Properties and Applications, 2016. 